\title{
TNFRSF14 deficiency protects against ovariectomy-induced adipose tissue inflammation
}

\author{
Eun-Kyung Choi*, Woon-Ki Kim*, Ok-Joo Sul, Yun-Kyung Park, Eun-Sook Kim', \\ Jae-Hee Suh ${ }^{2}$, Rina $\mathrm{Yu}^{3}$ and Hye-Seon Choi \\ Department of Biological Sciences, University of Ulsan, Ulsan 680-749, Korea \\ ${ }^{1}$ Department of Endocrinology, Ulsan University Hospital, Ulsan 682-714, Korea \\ ${ }^{2}$ Department of Pathology, Ulsan University Hospital, Ulsan 682-714, Korea \\ ${ }^{3}$ Department of Food Science and Nutrition, University of Ulsan, Ulsan 680-749, Korea \\ *(E-K Choi and W-K Kim contributed equally to this work)
}

Correspondence should be addressed to H-S Choi

Email

hschoi@mail.ulsan.ac.kr

\begin{abstract}
To elucidate the role of tumor necrosis factor receptor superfamily member 14 (TNFRSF14) in metabolic disturbance due to loss of ovarian function, ovariectomy (OVX) was performed in TNFRSF 14-knockout mice. OVX increased fat mass and infiltration of highly inflammatory CD11c cells in the adipose tissue (AT), which was analyzed by flow cytometry, and resulted in disturbance of glucose metabolism, whereas TNFRSF14 deficiency attenuated these effects. TNFRSF14 deficiency decreased recruitment of CD11c-expressing cells in AT and reduced the polarization of bone marrow-derived macrophages to M1. Upon engagement of LIGHT, a TNFRSF14 ligand, TNFRSF14 enhanced the expression of CD11c via generation of reactive oxygen species, suggesting a role of TNFRSF14 as a redox modulator. TNFRSF14 participated in OVX-induced AT inflammation via upregulation of CD11C, resulting in metabolic perturbation. TNFRSF14 could be used as a therapeutic target for the treatment of postmenopausal syndrome by reducing AT inflammation.
\end{abstract}
Key Words
- adipose tissue
- inflammatory diseases
- ovarian function
- menopause
- glucose metabolism

\section{Introduction}

Menopause increases the incidence of metabolic diseases. The loss of ovarian function is associated with increased visceral fat along with metabolic pathologies due to chronic inflammation (Shoelson et al. 2007). The ovariectomy (OVX) model in mice is commonly accepted to reflect human menopause. OVX increased body weight and chronic inflammation (Rogers et al. 2009), indicating that increased fat is associated with inflammation, leading to the metabolic complications observed in OVX. Increased fat leads to the accumulation of adipose tissue macrophage (ATM), which plays a critical role in chronic inflammation and development of insulin resistance (IR) (Shoelson et al. 2007). Exacerbation of insulin sensitivity is related to the increased ATM (Kanda et al. 2006). Inversely, decreased ATM reduces IR caused by diet-induced obesity (Lesniewski et al. 2007). The local metabolic microenvironment affects phenotypes of predominant cells, leading to heterogeneous ATM. Macrophages are classified into two populations, one of which expresses CD11c, an M1 macrophage marker specifically recruited to adipose tissue (AT) in obesity (Lumeng et al. 2007). M1 ATM produces proinflammatory cytokines such as tumor necrosis factor $\alpha$ (TNF $\alpha$ ), interleukin 6 (IL6), and monocyte chemoattractant protein 1, which contribute to the induction of IR, indicating a connection between CD11c expression and IR. M2 ATMs have different expression patterns, with a high

Published by Bioscientifica Ltd 
level of CD163, arginase-1, or IL10 that are mainly associated with tissue repair (Gordon \& Taylor 2003).

TNF receptor superfamily 14 (TNFRSF14) is a TNF receptor family member and was originally identified as the receptor for herpes simplex virus 1 (Montgomery et al. 1996). TNFRSF14 was initially identified to act as a co-stimulator in T-cells, and cross-linking of LIGHT, a TNF family member, to TNFRSF14 stimulates T-cells and accelerates proliferation and cytokine production (Tamada et al. 2000). TNFRSF14 is expressed constitutively on myeloid lineage cells and is also strongly expressed on nonimmune cells such as endothelial cells and adipocytes (Bassols et al. 2010a), suggesting that TNFRSF14 participates in metabolism as well as immune modulation. TNFRSF14 transmits a signal that leads to the activation of NF- $\kappa B$ (Marsters et al. 1997), a transcriptional regulator of inflammatory genes, suggesting a link between TNFRSF14 and inflammatory metabolic diseases. LIGHT, which is released in platelets, has been demonstrated to induce an inflammatory response in monocytes (Otterdal et al. 2006) and to mediate upregulation of matrix metalloproteinases (MMPs) and intercellular adhesion molecule 1 in monocytes, resulting in aggravation of rheumatic arthritis (Kang et al. 2007). Cross-linking of TNFRSF14 and its ligand is also involved in the development of inflammatory diseases by recruiting immune cells and releasing inflammatory cytokines (Kim et al. 2011a). Lack of TNFRSF14 reduces high-fat diet (HFD)-induced IR (Kim et al. 2011b). LIGHT is also associated with hyperglycemia in obese subjects (Bassols et al. 2010b).

In this study, we investigated the role of TNFRSF14 in OVX-induced AT inflammation to cause metabolic perturbation in mice.

\section{Materials and methods}

\section{Animals and study design}

TNFRSF14 $4^{-1-}$ (TNFRSF14-knockout (KO)) mice with a C57BL/6 genetic background were prepared as described previously (Kim et al. 2011c) and were provided by the Immunomodulation Research Center (IRC), University of Ulsan. The genotypes of offspring were determined by Southern blot analysis of DNA from tail biopsies. All mice were housed in the specific pathogen-free animal facility of the IRC and were handled in accordance with the guidelines of the Institutional Animal Care and Use Committee (IACUC) of the IRC. The standards were approved by that Committee (2008-033). Six-week-old female TNFRSF $14^{+/+}(\mathrm{WT})$ and TNFRSF $14^{-/-}(\mathrm{KO})$ mice were subjected to OVX or sham operation. Food intake and body weight were monitored daily and weekly respectively. After 12 weeks, mice were fasted for $6 \mathrm{~h}$ and killed by cervical dislocation. Blood was collected by cardiac puncture, and tissues were immediately harvested. Blood glucose was measured with a commercially available enzyme assay kit (Asan Pharmacology, Hwa-Seong, Korea). Glucose and insulin tolerance tests were performed on $6 \mathrm{~h}$ fasted mice. For glucose tolerance, animals were injected i.p. with glucose $(1 \mathrm{mg} / \mathrm{kg})$, whereas for insulin tolerance, $0.75 \mathrm{~m}$-units $/ \mathrm{kg}$ of recombinant human regular insulin (Eli Lilly) was injected i.p. Blood samples were drawn at $0,15,30,60,90$, and $120 \mathrm{~min}$ after glucose injection or $0,15,30,60,90$, and $120 \mathrm{~min}$ after insulin injection. Serum $\mathrm{H}_{2} \mathrm{O}_{2}$ was determined by Amplex Red hydrogen peroxide/peroxidase assay kit (Invitrogen).

\section{Stromal vascular cell isolation}

Visceral fat pads were weighed, rinsed three times in PBS, and minced with fluorescence-activated cell sorter (FACS) buffer (PBS with 1\% BSA). Tissue suspensions were centrifuged at $500 \boldsymbol{g}$ for $5 \mathrm{~min}$ and then treated with type 2 collagenase $(1 \mathrm{mg} / \mathrm{ml}$; Sigma Chemical) for $90 \mathrm{~min}$ at $37^{\circ} \mathrm{C}$ by shaking. Cell suspensions were filtered through a $100 \mu \mathrm{m}$ filter and centrifuged at $500 \boldsymbol{g}$ for $5 \mathrm{~min}$. Stromal vascular cell (SVC) pellets were incubated with RBC lysis buffer (eBioscience, San Diego, CA, USA) for $5 \mathrm{~min}$, centrifuged at $300 \boldsymbol{g}$ for $5 \mathrm{~min}$, and resuspended in FACS buffer. SVC were incubated with Fc blocker for $20 \mathrm{~min}$ at $4{ }^{\circ} \mathrm{C}$ before staining fluorescently labeled antibodies against CD11b, CD11c, F4/80, CD4, and CD8 (eBioscience). Cells were gently washed twice, resuspended in FACS buffer, and analyzed using a FACSCanto II flow cytometer (Becton Dickinson, San Jose, CA, USA).

\section{Cell preparation}

Femora and tibiae were removed aseptically and dissected free of adherent soft tissue. The bone ends were cut and the marrow cavity was flushed out with $\alpha$-MEM (minimum essential media) from one end of the bone, using a sterile 21gauge needle. The bone marrow was further agitated using a Pasteur pipette to obtain a single-cell suspension, which was washed twice and incubated on plates with macrophage colony-stimulating factor (M-CSF) $(20 \mathrm{ng} / \mathrm{ml} ; \mathrm{R} \& \mathrm{D}$ Systems, Minneapolis, MN, USA) for $16 \mathrm{~h}$. Non-adherent cells were then harvested, layered on a Ficoll-Hypaque gradient, and cultured for two more days, by which time large populations of adherent monocyte-/macrophage-like cells had formed

Published by Bioscientifica Ltd. 
on the bottoms of the culture plates as previously described (Kim et al. 2012). The few non-adherent cells were removed by washing the dishes with PBS, and the adherent cells (bone marrow-derived macrophages (BMMs)) were harvested and seeded on plates. The adherent cells were analyzed by FACS and found to be negative for CD3 and CD45R and positive for $\mathrm{CD} 11 \mathrm{~b}$. The absence of contaminating stromal cells was confirmed by lack of cell growth in the absence of M-CSF. Additional medium with M-CSF was added and later refreshed on day 3. After incubation for the recommended times, the cells were analyzed using a FACSCanto II flow cytometer. BMM was transfected with siRNA against $\mathrm{p} 47^{\text {phox }}\left(\right.$ sip $47^{\text {phox }}$ ), or scrambled siRNA (scRNA) (Santa Cruz Biotechnology), using Lipofectamine RNAiMAX (Invitrogen) and further analyzed.

\section{Quantitative PCR}

Total RNA from BMMs incubated with M-CSF for the indicated time period was extracted using TRIzol solution (Gibco, Life Technologies) and reverse-transcribed with oligo-dT and Superscript I enzyme (Invitrogen). Quantitative PCR (qPCR) was carried out using SYBR Green 1 Taq polymerase (Qiagen) and appropriate primers on a DNA Engine Opticon Continuous Fluorescence Detection System (MJ Research, Inc., Quebec, Canada). The specificity of each primer pair was confirmed by melting curve analysis and agarose-gel electrophoresis. GAPDH was amplified in parallel with genes of interest. Relative copy numbers compared with GAPDH were calculated using $2^{-\Delta \Delta C t}$. The primer sequences used were as follows: $5^{\prime}$-ctggatagcctttcttctgctg- $3^{\prime}$ and $5^{\prime}$-gcacactgtgtccgaactc- $3^{\prime}$ (CD11c); $5^{\prime}$-cagctgggctgtacaaacctt- $3^{\prime}$ and $5^{\prime}$-cattggaagtgaagcgtttcg- $3^{\prime}$ (iNOS); $5^{\prime}$-tcgctcagggtcacaagaaa- $3^{\prime}$ and $5^{\prime}$-atcagaggcaaggaggaaacac-3' (IL1 $\beta$ ); $5^{\prime}$-gctcttactgactggcatgag-3' and $5^{\prime}$-cgcagctctaggagcatgtg- $3^{\prime}$ (IL10); and $5^{\prime}$-ctccaagccaaagtccttaga- $3^{\prime}$ and GAPDH, $5^{\prime}$-acccagaagactgtggatgg- $3^{\prime}$ and $5^{\prime}$-cacattgggggtaggaacac- $3^{\prime}$.

\section{Intracellular reactive oxygen species detection}

The intracellular formation of reactive oxygen species (ROS) was detected using the fluorescence probe, $2^{\prime}, 7^{\prime}$-dichlorofluorescein diacetate $\left(\mathrm{H}_{2}\right.$ DCF-DA; Molecular Probes, Eugene, OR, USA). After BMM was cultured under the different experimental conditions for 2 days, the cells were washed, trypsinized, suspended in PBS, loaded with $\mathrm{H}_{2}$ DCF-DA, and incubated at $37^{\circ} \mathrm{C}$ for $30 \mathrm{~min}$. The measurement of intracellular ROS was performed using flow cytometry with a FACS (FACSCanto II).

\section{Statistical analysis}

Values are expressed as mean \pm s.E.M. Student's $t$-test was used to evaluate differences between samples of interest and the corresponding controls. Differences between groups were assessed by one- or two-way ANOVA, followed by Bonferroni post-hoc tests. A $P$ value $<0.05$ was considered statistically significant.

\section{Results}

\section{TNFRSF14 deficiency decreases fat mass and metabolic perturbation induced by OVX}

To investigate whether TNFRSF14 contributes to OVXinduced metabolic dysfunction, we analyzed TNFRSF14KO mice compared with WT mice. The body weight increase in TNFRSF14-KO mice was slightly lower than that of WT mice at 12 weeks after sham surgery but not significantly (Table 1). No significant difference was found in visceral fat or subcutaneous fat between the two groups after sham surgery (Table 1), demonstrating that TNFRSF14 did not affect fat mass after sham surgery. Then, we performed OVX to assess the role of TNFRSF14 in metabolic disorder due to loss of ovarian function. Along with body weight, the fat masses of visceral and subcutaneous AT were significantly reduced in TNFRSF14-KO mice compared with WT mice after OVX (Table 1). However, neither OVX nor TNFRSF14 induced a significant difference in daily food intake (Table 1), suggesting that an altered metabolic rate may be responsible for the increased fat mass and body weight induced by OVX. Previously, we demonstrated that OVX induced oxidative stress (Phan et al. 2013), and the absence of TNFRSF14 decreases ROS levels in vitro (Kim et al. 2012). Elevated serum levels of $\mathrm{H}_{2} \mathrm{O}_{2}$ after OVX were significantly decreased in the absence of TNFRSF14 in vivo (Table 1). TNFRSF14 deficiency also reduced elevated levels of blood glucose and serum insulin induced by OVX (Table 1). To confirm that the absence of TNFRSF14 improved glucose tolerance aggravated by OVX, we determined glucose clearance following an i.p. injection of glucose. In OVX TNFRSF14-KO mice, the glucose level decreased significantly after glucose injection, and the area under the curve for glucose tolerance was also decreased compared with that of OVX WT mice (Fig. 1A). However, TNFRSF14 did not show any difference in sham mice. Next, after i.p. injected insulin was given to determine insulin sensitivity, glucose was cleared more effectively

Published by Bioscientifica Ltd. 
Table 1 Physiological measurements of sham and OVX of WT and TNFRSF14-KO mice 12 weeks after operation. Data are expressed as mean \pm S.E.M.

\begin{tabular}{|c|c|c|c|c|}
\hline \multirow[b]{2}{*}{ Variable } & \multicolumn{2}{|c|}{ WT } & \multicolumn{2}{|c|}{ TNFRSF14-KO } \\
\hline & Sham & ovx & Sham & ovx \\
\hline Increased body weight (g) & $5.886 \pm 0.3965$ & $8.871 \pm 0.4144$ & $4.968 \pm 0.2149$ & $6.467 \pm 0.6182 * *$ \\
\hline Subcutaneous fat (mg) & $288 \pm 55.89$ & $1029 \pm 198.8$ & $315 \pm 66.64$ & $633.3 \pm 128.3 * *$ \\
\hline Visceral fat (mg) & $327 \pm 9.460$ & $1213 \pm 155.1$ & $337 \pm 57.20$ & $777.6 \pm 220.1 * *$ \\
\hline Serum $\mathrm{H}_{2} \mathrm{O}_{2}(\mathrm{nmol} / \mathrm{ml})$ & $49.87 \pm 1.602$ & $66.62 \pm 3.545$ & $45.09 \pm 1.730$ & $55.67 \pm 1.641 * *$ \\
\hline Serum glucose (mg/dl) & $92.20 \pm 3.261$ & $125.75 \pm 5.878$ & $102.3 \pm 6.968$ & $107.4 \pm 5.626^{*}$ \\
\hline Serum insulin ( $\mathrm{ng} / \mathrm{ml})$ & $0.6030 \pm 0.04380$ & $0.8499 \pm 0.05070$ & $0.5454 \pm 0.07600$ & $0.6828 \pm 0.03790$ * \\
\hline Food intake (g/day) & $4.340 \pm 0.2300$ & $4.230 \pm 0.2800$ & $4.020 \pm 0.2300$ & $4.260 \pm 0.1800$ \\
\hline
\end{tabular}

Differences between groups were analyzed by two-way ANOVA, followed by Bonferroni post-hoc tests to compare the effect of TNFRSF14-KO deficiency (increased body weight, subcutaneous fat, visceral fat, serum $\mathrm{H}_{2} \mathrm{O}_{2}$, and serum insulin; $P<0.001$, serum glucose; $P<0.01$, effect of surgery. Increased body weight and serum insulin; $P<0.05$, serum $\mathrm{H}_{2} \mathrm{O}_{2} ; P<0.01$, effect of TNFRSF14). WT OVX vs TNFRSF14-KO OVX; $* P<0.05, * * P<0.01$.

in OVX TNFRSF14-KO mice compared with OVX WT mice (Fig. 1B), indicating that the lack of TNFRSF14 improved insulin sensitivity upon OVX.

\section{TNFRSF14 deficiency decreases M1 macrophages in AT induced by OVX}

The findings that ATM accumulated during obesity result in IR (Xu et al. 2003) and TNFRSF14 mediates macrophage recruitment in tissues (Kim et al. 2011a) prompted us to further link the cause of improved glucose clearance observed in OVX TNFRSF14-KO mice to attenuated ATM. To assess AT inflammation induced by OVX, we evaluated SVC of the visceral fat pad by flow cytometry. A profound increase in ATM was found in OVX WT mice, whereas strikingly fewer ATMs accumulated in OVX TNFRSF14-KO mice, although the level was not completely rescued to that of sham WT mice (Fig. 2A). As shown in Fig. 2B, C and D, OVX increased cell numbers of CD11cF4/80, CD4, and CD8 in WT mice, whereas TNFRSF14 deficiency significantly reduced all numbers, suggesting that TNFRSF14 plays a role in increasing immune cells in AT upon OVX.

As the M1 macrophage expressing CD11c is responsible for chronic inflammation and insulin sensitivity (Patsouris et al. 2008), we focused on investigating the precise mechanism of how TNFRSF14 acts to increase CD11c macrophages in AT. First, we sought to determine whether this increase is due to an increased influx of CD11c-expressing cells in AT and/or increased activation of bone marrow-derived precursors into CD11c-expressing M1 macrophages in residential tissues. Using CD11b as a marker of monocytes, we classified blood monocytes as $\mathrm{CD}_{11 \mathrm{c}^{+}}$or $\mathrm{CD} 11 \mathrm{c}^{-}$cells. Significant increase in the fraction of CD11c cells among total leukocytes was observed in OVX mice compared with sham mice (Fig. 3A). TNFRSF14 deficiency reduced blood CD11c cells upon OVX, indicating that TNFRSF14 plays a role in the recruitment of $\mathrm{CD} 11 \mathrm{c}$ cells in AT.

Next, to assess whether TNFRSF14 affects phenotypes of macrophage in residential tissues, bone marrow-derived precursors were exposed to M-CSF. After a 4-day exposure of M-CSF to BMM, $\sim 20 \%$ of total cells expressed CD11c and F4/80, and the lack of TNFRSF14 reduced this

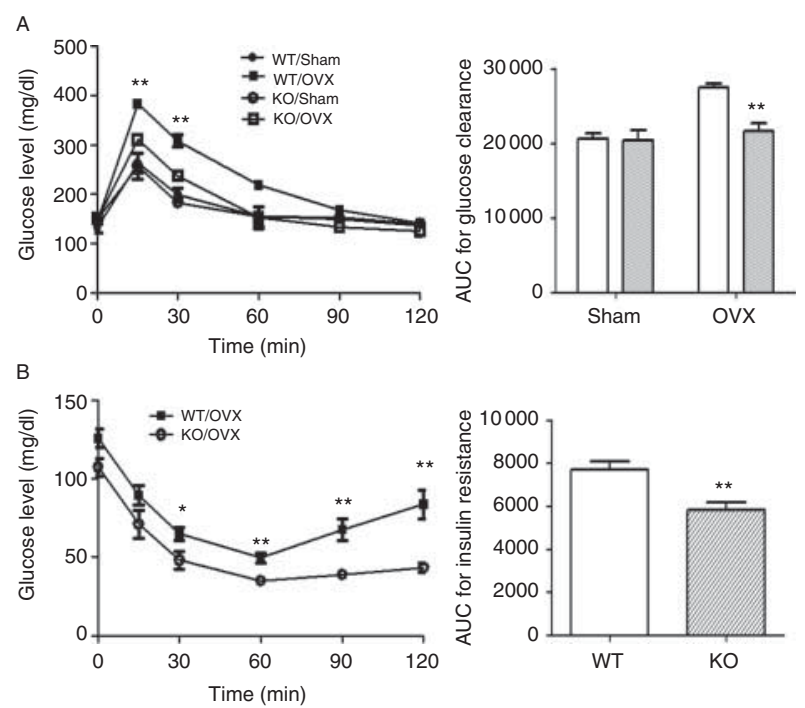

\section{Figure 1}

TNFRSF14 deficiency improved metabolic perturbation induced by OVX. WT (open bar) and TNFRSF14-KO mice (oblique-lined bar) were subjected to OVX or sham surgery for 12 weeks. Glucose clearance $(A)$ and insulin sensitivity $(B)$ were determined at 12 weeks after sham or OVX following an i.p. injection of glucose $(1 \mathrm{mg} / \mathrm{kg})$ or insulin $(0.75 \mathrm{~m}$-units $/ \mathrm{kg})$ respectively. $* P<0.05,{ }^{*} P<0.01$ vs TNFRSF14-KO OVX mice. Area under the curve (AUC) was measured for each group ( $A$ and $B$ ), and analyzed by two-way ANOVA followed by Bonferroni post-hoc tests ( $* * P<0.01$, effect of surgery; $\star P<0.05$, effect of TNFRSF14; $* * P<0.01$ vs WT OVX mice). http://joe.endocrinology-journals.org DOI: 10.1530/JOE-13-0341
(C) 2014 Society for Endocrinology Printed in Great Britain 

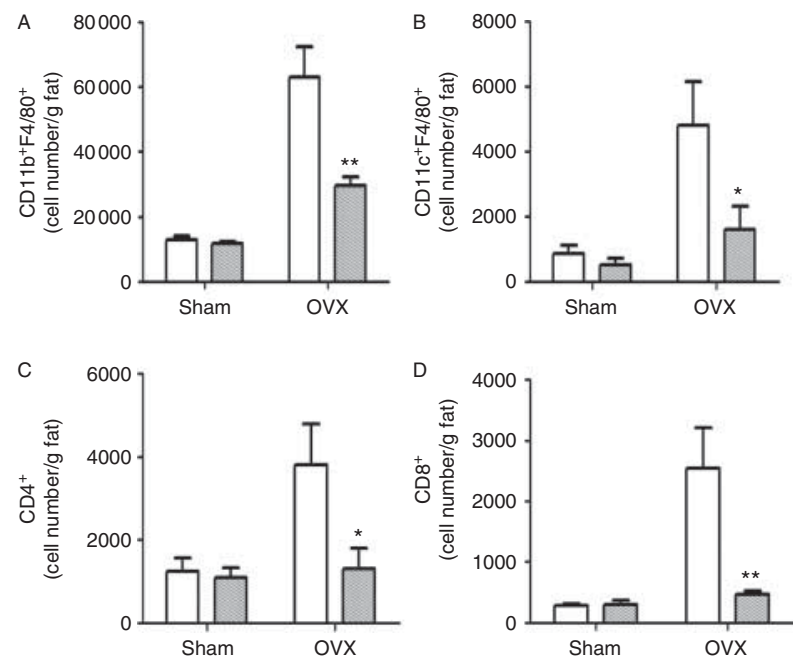

Figure 2

TNFRSF14 deficiency decreased OVX-induced immune cell infiltration in AT. SVCs from visceral fat were extracted from WT (open bar) and TNFRSF14-KO mice (oblique-lined bar) 12 weeks after sham or OVX surgery. SVCs were labeled with conjugated Abs to CD11bF4/80 (A), CD11cF4/80 (B), CD4 (C), and CD8 (D), quantified by FACS, and analyzed by two-way ANOVA followed by Bonferroni post-hoc tests (CD11bF4/80, CD11cF4/80, CD4, CD8; $P<0.05$, effect of TNFRSF14, CD4, CD8; $P<0.05$, CD11cF4/80; $P<0.01, \mathrm{CD} 11 \mathrm{bF} 4 / 80 ; P<0.001$, effect of surgery; ${ }^{\star} P<0.05$, $* * P<0.01$ vs WT OVX mice.).

percentage significantly (Fig. 3B). To analyze other characteristics of M-CSF-stimulated cells, we compared the transcript levels of specific markers. The absence of TNFRSF14 resulted in a decreased level of CD11c, IL1 $\beta$, and iNOS and increased levels of arginase-1 and IL10 compared with WT cells (Fig. 3C), demonstrating that the absence of TNFRSF14 reduced the ability of BMM to express M1 specific characteristics. To confirm that the decreased CD11c expression observed in TNFRSF14-KO BMMs was due to lack of a signal through TNFRSF14, we examined the effect of LIGHT on CD11c expression. LIGHT was constitutively expressed in BMMs as shown previously (Kim et al. 2012). Soluble LIGHT (sLIGHT) significantly increased CD11c expression in WT cells but had no effect on TNFRSF14-KO cells (Fig. 3B), suggesting that LIGHT transmits a signal through TNFRSF14 leading to CD11c expression. To provide further evidence that a signal through TNFRSF14 is responsible for CD11c expression, we attempted to compete out membranebound TNFRSF14 with soluble TNFRSF14 (sTNFRSF14). sTNFRSF14 significantly reduced the expression of CD11c in WT cells but had no effect in the TNFRSF14-KO cells (Fig. 3B). These results demonstrated that the LIGHTTNFRSF14 interaction is a positive regulator of CD11c expression via a signal through TNFRSF14.

\section{TNFRSF14 induces CD11c expression via generation of ROS}

As TNFRSF14 deficiency blunted M-CSF-induced CD11c expression in BMM, we investigated a mediator generated by TNFRSF14 to upregulate the expression of CD11c. It is known that oxidative stress induced by OVX was attenuated in the absence of TNFRSF14, and ROS contributes to increased CD11c expression (Moon et al. 2006). Thus, we assessed the association of ROS in CD11c expression with TNFRSF14-involved signaling. Exogenous $\mathrm{H}_{2} \mathrm{O}_{2}$ elevated CD11c in WT cells and completely recovered the decreased level of $\mathrm{CD} 11 \mathrm{c}$ observed in TNFRSF14-KO cells (Fig. 4A). Decreased ROS levels due to

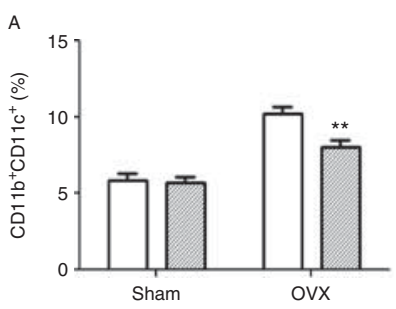

B
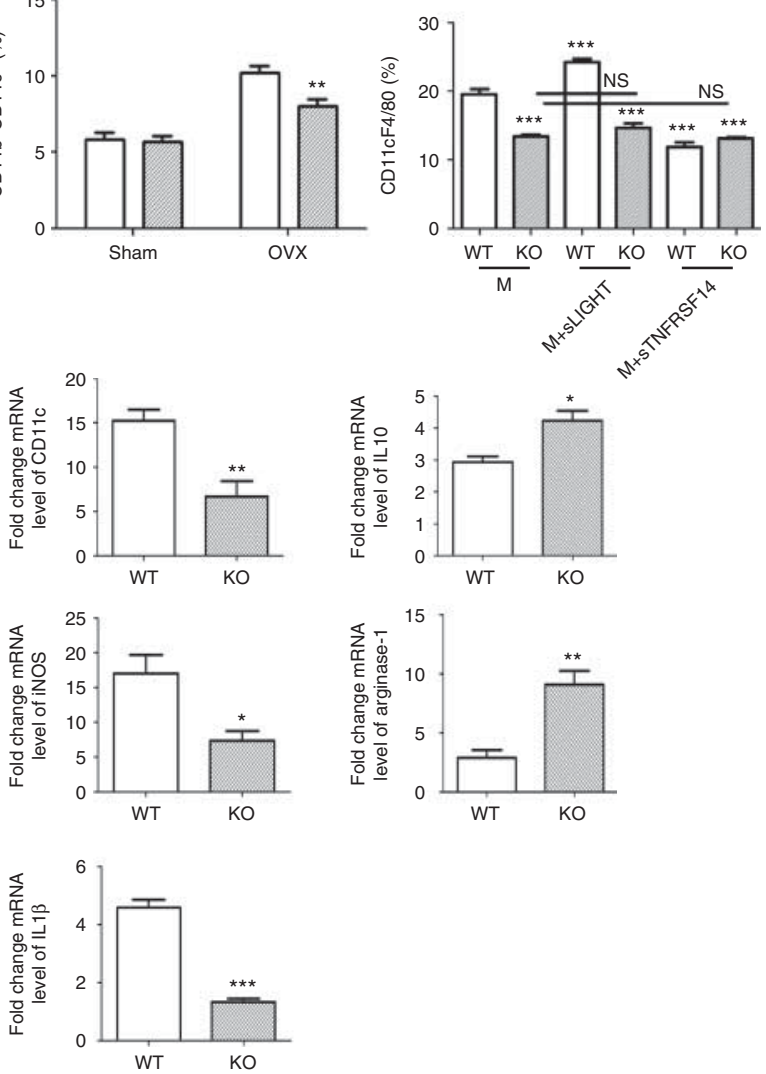

Figure 3

TNFRSF14 deficiency decreased CD11c via reduced recruitment and attenuated activation upon M-CSF stimulation. CD11 ${ }^{+}$and $\mathrm{CD}_{11 \mathrm{C}^{-}}$ monocytes in the blood of WT (open bar) and TNFRSF14-KO mice (obliquelined bar) 12 weeks after sham or OVX surgery, and analyzed by two-way ANOVA followed by Bonferroni post-hoc tests $(* * * P<0.001$, effect of surgery; ${ }^{*} P<0.05$, effect of TNFRSF14; $* * P<0.01$ vs WT OVX mice) (A). BMMs were stimulated using M-CSF (M; $30 \mathrm{ng} / \mathrm{ml})$ with or without sLIGHT $(10 \mathrm{ng} / \mathrm{ml})$ or STNFRSF14 $(20 \mathrm{ng} / \mathrm{ml})$ for 4 days and were labeled with conjugated $\mathrm{Abs}$ to $\mathrm{CD} 11 \mathrm{c}$ and $\mathrm{F} 4 / 80$. $* * * P<0.001$ vs M-stimulated WT cells (B). BMMs were stimulated with M-CSF for 2 days, and total RNA was extracted and subjected to qPCR analysis. The expression level of prior M-CSF treatment was set to be 1.0 (C). ${ }^{*} P<0.05,{ }^{* *} P<0.01, * * * P<0.001$ vs WT cells.

Published by Bioscientifica Ltd 


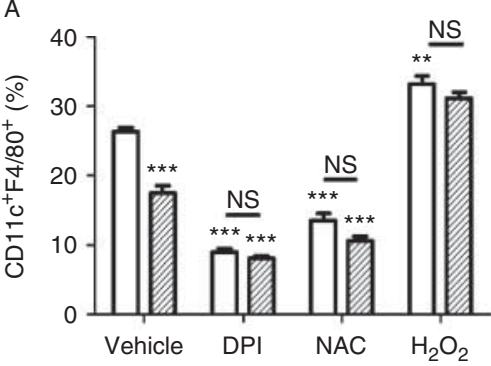

C
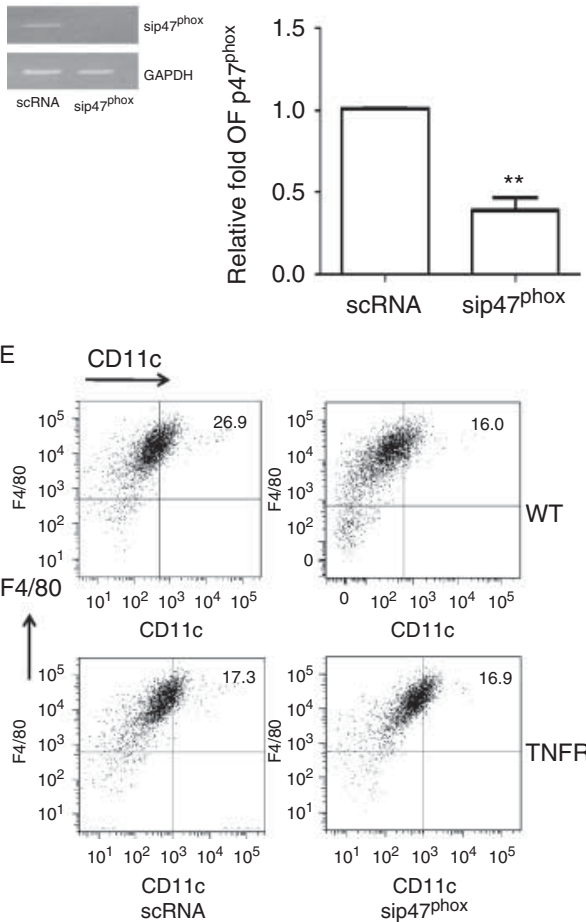

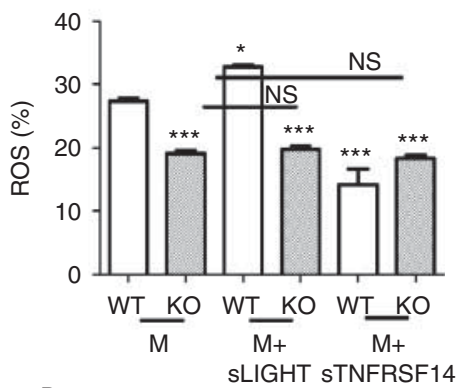

$\mathrm{D}$

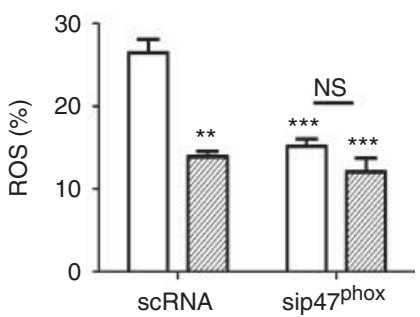

Figure 4

TNFRSF14 deficiency decreased CD11c-expressing cells by impairing the production of ROS. BMMs from WT (open bar) and TNFRSF14-KO mice (oblique-lined bar) were incubated in the presence of M-CSF $(30 \mathrm{ng} / \mathrm{ml}$ ) with vehicle, diphenylene iodonium (DPl; $20 \mathrm{nM}$ ), $\mathrm{N}$-acetylcysteine (NAC; $3 \mathrm{mM})$, or $\mathrm{H}_{2} \mathrm{O}_{2}(300 \mu \mathrm{M})$ for 4 days. ${ }^{* * P}<0.01,{ }^{* * * P}<0.001$ vs vehicletreated WT cells (A). Intracellular levels of ROS upon stimulation of M-CSF (M) with sLIGHT $(10 \mathrm{~g} / \mathrm{ml})$ or sTNFRSF14 $(20 \mathrm{ng} / \mathrm{ml})$ for 2 days were determined in BMMs using $\mathrm{H}_{2}$ DCFDA. $* P<0.05, * * * P<0.01$ vs

diphenylene iodonium (NADPH oxidase inhibitor) or exposure to $\mathrm{N}$-acetylcysteine also decreased the expression level of CD11c in WT BMM, but no further decrease was observed in the absence of TNFRSF14 (Fig. 4A). These results suggested that ROS play a positive role in the elevation of CD11c in BMM upon M-CSF stimulation, and that TNFRSF14 is associated with ROS generation to upregulate CD11c expression. Next, we confirmed that the LIGHT-TNFRSF14 interaction is involved in
M-stimulated WT cells (B). BMMs were transfected with sip47 $7^{\text {phox }}$ or scRNA. Downregulation of $\mathrm{p} 47^{\text {phox }}$ by sip $47^{\text {phox }}$ was confirmed by RT-PCR and $\mathrm{qPCR}$ (C). The expression level obtained from scRNA-treated cells was set to be 1 . $* * P<0.01$ vs scRNA-transfected cells. After $24 \mathrm{~h}$ of transfection with siRNA, cells were stimulated further with M-CSF for 2 days to measure ROS (D) and for 2 days (mRNA) or 4 days (FACS) to determine CD11c (E). **P<0.01, $* * * P<0.001$ vs scRNA-transfected WT cells.

M-CSF-induced ROS levels. M-CSF resulted in ROS production in WT BMM, but the absence of TNFRSF14 reduced this production (Fig. 4B). sLIGHT increased ROS while sTNFRSF14 decreased ROS in WT cells, but neither had an effect on ROS in TNFRSF14-KO cells (Fig. 4B), indicating that sLIGHT sends a signal through TNFRSF14 to upregulate ROS level upon M-CSF stimulation. To confirm that TNFRSF14 mediates signaling to express CD11c via generation of ROS, sip $47^{\text {phox }}$ or 
scRNA was transfected to BMM. Downregulation of p47 ${ }^{\text {phox }}$ (Fig. 4C) decreased ROS levels as well as the fraction of M-CSF-induced CD11c cells in WT BMM, whereas no further decreases were observed in TNFRSF14-KO cells (Fig. 4D and E).

\section{Discussion}

We have demonstrated that the absence of TNFRSF14 attenuated AT inflammation by reducing CD11c-expressing cells (Fig. 5) and improved metabolic disturbance induced by OVX. However, TNFRSF14 did not affect these factors in mice that received sham surgery, indicating that TNFRSF14 may mediate chronic inflammation induced by loss of ovarian function. In this study, OVX increased fat mass and CD11c-expressing ATM as well as CD11bF4/80, CD4, and CD8 T-cells. CD11c-expressing cells show proinflammatory characteristics of classically activated M1 macrophages (Lumeng et al. 2007) and generate proinflammatory cytokines, contributing to obesity-induced AT inflammation (Wu et al. 2010). Depletion of CD11c leads to a dramatic decrease in both local and systemic inflammatory markers in obese mice (Patsouris et al. 2008), supporting a role for CD11c in inflammation. Increased fat results in an increase in ATM (Shoelson et al. 2007), which is responsible for generating proinflammatory cytokines to develop IR. Development of IR has been promoted by proinflammatory cytokines (Stienstra et al. 2010), but attenuated by anti-inflammatory cytokines (Hong et al. 2009). To develop IR, the importance of macrophages has been implicated by the findings. The adipocyte-specific overexpression of heme oxygenase 1 (HO1) does not protect against HFD-induced obesity or IR (Huang et al. 2013), whereas myeloid HO1 haploinsufficiency attenuates these conditions (Huang et al. 2012). Our study also showed that the number of M1 macrophages in AT and the expression of CD11c, IL1 $\beta$, and iNOS in BMM were decreased in the absence of TNFRSF14. In contrast, the expression of IL10 and arginase-1 was elevated in TNFRSF14 deficiency. These findings suggested that TNFRSF14 plays a role in the disrupted glucose metabolism due to loss of ovarian function at least in part through the polarization of macrophages to M1.

Next, we demonstrated how TNFRSF14 was involved in the upregulation of CD11c expression in AT upon OVX. The lack of TNFRSF14 attenuated the influx of blood CD11c cells as well as CD11b cells, which were significantly elevated by OVX. We cannot exclude the contribution of blood neutrophils to the elevated level of CD11bCD11c upon OVX, because blood neutrophils also express CD11bCD11c. However, their infiltration in AT

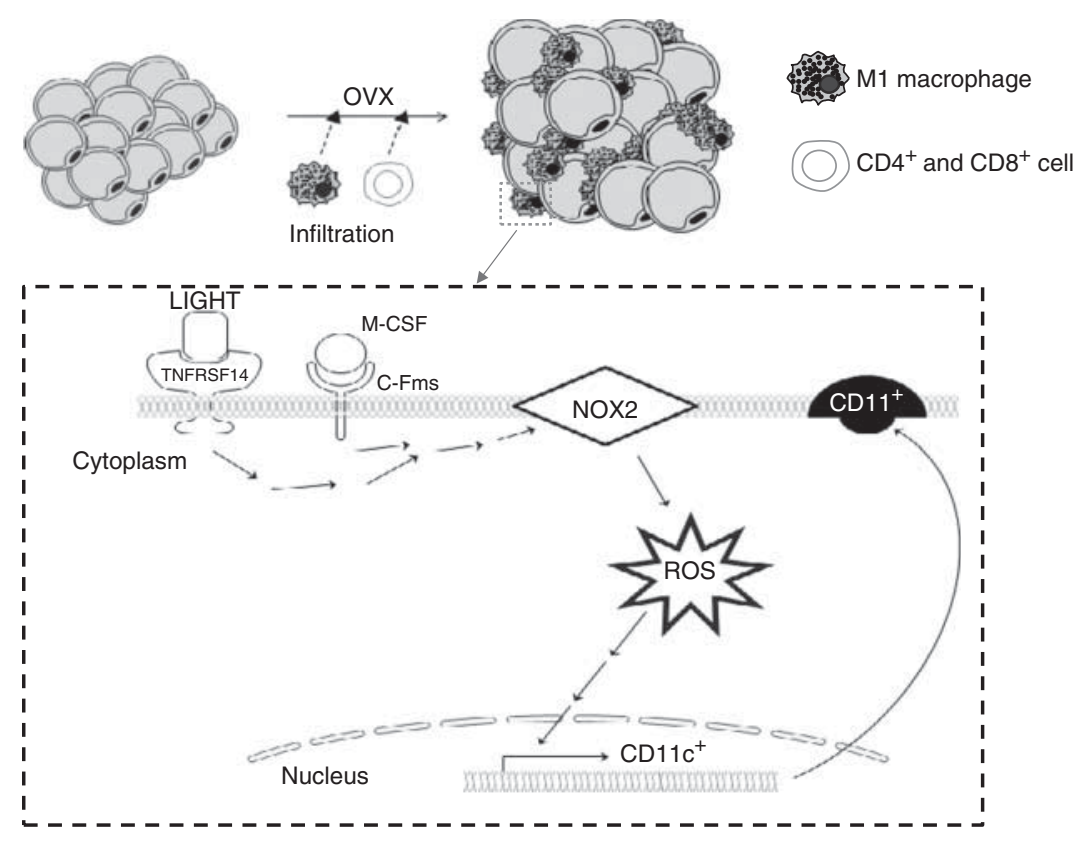

Figure 5

Schematic presentation for OVX-induced infiltration of M1 macrophages in AT. Upon LIGHT stimulation, TNFRSF14 on macrophages acts as a potent stimulator of M-CSF/c-Fms signaling pathway for ROS production, resulting in elevated CD11c expression.

http://joe.endocrinology-journals.org DOI: $10.1530 / \mathrm{JOE}-13-0341$
C 2014 Society for Endocrinology Printed in Great Britain
Published by Bioscientifica Ltd. 
has been reported to be negligible compared with F4/80expressing cells $(\sim 50$-folds lower $)$ when serum insulin level starts to rise with exhibiting IR (Komori et al. 2013). In addition to CD11c-expressing macrophages, TNFRSF14 deficiency reduced the infiltration of immune cells including CD11bF4/80, CD4, and CD8 T-cells in AT upon OVX, which induced them significantly, suggesting a role of TNFRSF14 in immune cell infiltration in AT. TNFRSF14 has been demonstrated to participate in the recruitment of macrophages and T-cells in vitro (Kim et al. 2011a). Accordingly, increased CD11c in AT upon OVX could be due to polarization of macrophages in AT. OVX increased serum level of M-CSF (Ke et al. 2012), which may promote the elevation of CD11c in AT. Decrease in CD11c cells is observed in mice lacking functional M-CSF (MacDonald et al. 2005), indicating that M-CSF is required for signaling in CD11c expression in vivo. Our data showed that M-CSF-induced CD11c expression was attenuated in the absence of TNFRSF14. sLIGHT increased CD11c and sTNFRSF14 decreased it in WT BMM, suggesting that LIGHT transmits the signal through TNFRSF14 to upregulate CD11c expression.

Loss of ovarian function significantly increased serum ROS in mice (Phan et al. 2013), and menopause causes oxidative stress in humans (Sanchez-Rodriguez et al. 2012). Elevation of ROS contributes to development of diabetes (Li et al. 2012) as well as upregulation of CD11c expression (Moon et al. 2006), suggesting that oxidative stress induced by OVX contributes to the elevation of CD11c expression. We showed that exogenous $\mathrm{H}_{2} \mathrm{O}_{2}$ increased CD11c expression in BMM upon M-CSF stimulation and rescued the decrease induced by TNFRSF14 deficiency. Knockdown of $\mathrm{p} 47^{\text {phox }}$ attenuated the differences of CD11c expression as well as ROS level due to the presence of TNFRSF14, indicating that ROS generation is mediated by TNFRSF14 to upregulate CD11c. In vivo TNFRSF14 deficiency reduced elevated serum ROS levels induced by OVX, suggesting that TNFRSF14 may be a mediator of increased redox level caused by loss of ovarian function. Consistently, our previous finding demonstrated that lack of TNFRSF14 reduced ROS levels upon RANKL stimulation in vitro (Kim et al. 2012).

Taken together, we showed that engagement of TNFRSF14 upregulated CD11c expression in BMM via ROS generation, resulting in chronic inflammation which contributes to impaired glucose metabolism due to loss of ovarian function. Understanding the role of TNFRSF14 in OVX-induced metabolic disturbances could aid in the design of a novel therapy for postmenopausal syndrome.

\section{Declaration of interest}

The authors declare that there is no conflict of interest that could be perceived as prejudicing the impartiality of the research reported.

\section{Funding}

This work was supported by Korea Healthcare Technology R\&D Project, Ministry of Health, Welfare and Family Affairs, Republic of Korea (A111295) funded by the Korean government.

\section{References}

Bassols J, Moreno JM, Ortega F, Ricart W \& Fernandez-Real JM $2010 a$ Characterization of herpes virus entry mediator as a factor linked to obesity. Obesity 18 239-246. (doi:10.1038/oby.2009.250)

Bassols J, Moreno-Navarrete JM, Ortega F, Ricart W \& Fernandez-Real JM $2010 b$ LIGHT is associated with hypertriglyceridemia in obese subjects and increased cytokine secretion from cultured human adipocytes. International Journal of Obesity 34 146-156. (doi:10.1038/ijo.2009.199)

Gordon S \& Taylor PR 2003 Monocyte and macrophage heterogeneity. Nature Reviews. Immunology 5 953-964. (doi:10.1038/nri1733)

Hong EG, Ko HJ, Cho YR, Kim HJ, Ma Z, Yu TY, Friedline RH, Kurt-Jones E, Finberg R, Fischer MA et al. 2009 Interleukin-10 prevents diet-induced insulin resistance by attenuating macrophage and cytokine response in skeletal muscle. Diabetes 58 2525-2535. (doi:10.2337/db08-1261)

Huang JY, Chiang MT, Yet SF \& Chau LY 2012 Myeloid heme oxygenase-1 haploinsufficiency reduces high fat diet-induced insulin resistance by affecting adipose macrophage infiltration in mice. PLOS ONE 7 e38626. (doi:10.1371/journal.pone.0038626)

Huang JY, Chiang MT \& Chau LY 2013 Adipose overexpression of heme oxygenase-1 does not protect against high fat diet-induced insulin resistance in mice. PLoS ONE 8 e55369. (doi:10.1371/journal.pone. 0055369)

Kanda H, Tateya S, Tamori Y, Kotani K, Hiasa K, Kitazawa R, Kitazawa S, Miyachi H, Maeda S, Egashira K et al. 2006 MCP-1 contributes to macrophage infiltration into adipose tissue, insulin resistance, and hepatic steatosis in obesity. Journal of Clinical Investigation 116 1494-1505. (doi:10.1172/JCI26498)

Kang YM, Kim SY, Kang JH, Han SW, Nam EJ, Kyung HS, Park JY \& Kim IS 2007 LIGHT up-regulated on B lymphocytes and monocytes in rheumatoid arthritis mediates cellular adhesion and metalloproteinase production by synoviocytes. Arthritis and Rheumatism 56 1106-1117. (doi:10.1002/art.22493)

Ke K, Kim WK, Sul OJ, Phan VT, Lee MH, Kim HJ, Kim SY \& Choi HS 2012 The elevation of fibrinogen due to loss of ovarian function enhances actin ring formation and leads to increased bone resorption. American Journal of Physiology. Endocrinology and Metabolism 303 E1296-E1303. (doi:10.1152/ajpendo.00085.2012)

Kim HM, Jeong CS, Choi HS, Kawada T \& Yu R 2011a LIGHT/TNFSF14 enhances adipose tissue inflammatory responses through its interaction with HVEM. FEBS Letters 585 579-584. (doi:10.1016/ j.febslet.2011.01.011)

Kim HJ, Kim HM, Kim CS, Jeong CS, Choi HS, Kawada T, Kim BS \& Yu R $2011 b$ HVEM-deficient mice fed a high-fat diet are protected from adipose tissue inflammation and glucose intolerance. FEBS Letters $\mathbf{5 8 5}$ 2285-2290. (doi:10.1016/j.febslet.2011.05.057)

Kim WK, Park JS, Sul OJ, Seo JH, Choi BK, Park HY, Latour AM, Koller BH, Kwon BS \& Jeong CS 2011c Role of TNFR-related 2 mediated immune responses in dextran sulfate sodium-induced inflammatory bowel disease. Molecular Cell 31 99-104. (doi:10.1007/s10059-011-0013-y)

Kim WK, Sul OJ, Choi EK, Lee MH, Jeong CS, Kim HJ, Kim SY, Suh JH, Yu R \& Choi HS 2012 Absence of herpes virus entry mediator (HVEM) increases bone mass by attenuating receptor activator of nuclear http://joe.endocrinology-journals.org DOI: 10.1530/JOE-13-0341
C 2014 Society for Endocrinology Printed in Great Britain 
factor- $\mathrm{kB}$ ligand (RANKL)-induced osteoclastogenesis. Endocrinology 153 4808-4817. (doi:10.1210/en.2012-1079)

Komori T, Tanaka M, Senba E, Miyajima A \& Morikawa Y 2013 Lack of oncostatin $\mathrm{M}$ receptor $\beta$ leads to adipose tissue inflammation and insulin resistance by switching macrophage phenotype. Journal of Biological Chemistry 288 21861-21875. (doi:10.1074/jbc.M113.461905)

Lesniewski LA, Hosch SE, de Luca JG, Neels C, Pashmforoush M, Lumeng CN, Chiang SH, Scadeng M, Saltiel AR \& Olefsky JM 2007 Bone marrowspecific Cap gene deletion protects against high-fat diet-induced insulin resistance. Nature Medicine 13 455-462. (doi:10.1038/nm1550)

Li J, Sipple J, Maynard S, Mehta PA, Rose SR, Davies SM \& Pang Q 2012 Fanconi anemia links reactive oxygen species to insulin resistance and obesity. Antioxidants \& Redox Signaling 17 1083-1098. (doi:10.1089/ars. 2011.4417)

Lumeng CN, Bodzin JL \& Saltiel AR 2007 Obesity induces a phenotypic switch in adipose tissue macrophage polarization. Journal of Clinical Investigation 117 175-184. (doi:10.1172/JCI29881)

MacDonald KP, Rowe V, Bofinger HM, Thomas R, Sasmono T, Hume DA \& Hill GR 2005 The colony-stimulating factor 1 receptor is expressed on dendritic cells during differentiation and regulates their expansion. Journal of Immunology 175 1399-1405.

Marsters SA, Ayres TM, Skubatch M, Gray CL, Rothe M \& Ashkenazi A 1997 Herpesvirus entry mediator, a member of the tumor necrosis factor receptor (TNFR) family, interacts with members of the TNFR-associated factor family and activates the transcription factors NF- $\kappa \mathrm{B}$ and AP-1. Journal of Biological Chemistry 272 14029-14032. (doi:10.1074/jbc.272. 22.14029)

Montgomery RI, Warner MS, Lum BJ \& Spear PG 1996 Herpes simplex virus 1 entry into cells mediated by a novel member of the TNF/NGF receptor family. Cell 87 427-436. (doi:10.1016/S00928674(00)81363-X)

Moon EY, Noh YW, Han YH, Kim SU, Kim JM, Yu DY \& Lim JS 2006 $\mathrm{T}$ lymphocytes and dendritic cells are activated by the deletion of peroxiredoxin II (Prx II) gene. Immunology Letters 102 184-190. (doi:10.1016/j.imlet.2005.09.003)

Otterdal K, Smith C, Oie E, Pedersen TM, Yndestad A, Stang E, Endresen K, Solum NO, Aukrust P \& Damås JK 2006 Platelet-derived LIGHT induces inflammatory responses in endothelial cells and monocytes. Blood $\mathbf{1 0 8}$ 928-935. (doi:10.1182/blood-2005-09-010629)
Patsouris D, Li P, Thapar D, Chapman J, Olefsky JM \& Neels JG 2008 Ablation of CD11c-positive cells normalizes insulin sensitivity in obese insulin resistant animals. Cell Metabolism 8 301-309. (doi:10.1016/ j.cmet.2008.08.015)

Phan TV, Sul OJ, Ke K, Lee MH, Kim WK, Cho YS, Kim HJ, Kim SY, Chung HT \& Choi HS 2013 Carbon monoxide protects against ovariectomy-induced bone loss by inhibiting osteoclastogenesis. Biochemical Pharmacology 85 1145-1152. (doi:10.1016/j.bcp.2013. 01.014)

Rogers NH, Perfield JW II, Strissel KJ, Obin MS \& Greenberg AS 2009 Reduced energy expenditure and increased inflammation are early events in the development of ovariectomy-induced obesity. Endocrinology 150 2161-2168. (doi:10.1210/en.2008-1405)

Sanchez-Rodriguez MA, Zacarias-Flores M, Arronte-Rosales A, Correa-Munoz E \& Mendoza-Nunez VM 2012 Menopause as risk factor for oxidative stress. Menopause 19 361-367. (doi:10.1097/ gme.0b013e318229977d)

Shoelson SE, Herrero L \& Naaz A 2007 Obesity, inflammation, and insulin resistance. Gastroenterology 132 2169-2180. (doi:10.1053/j.gastro.2007. 03.059)

Stienstra R, Joosten LA, Koenen T, van Tits B, van Diepen JA, van den Berg SA, Rensen PC, Voshol PJ, Fantuzzi G, Hijmans A et al. 2010 The inflammasome-mediated caspase- 1 activation controls adipocyte differentiation and insulin sensitivity. Cell Metabolism 12 593-605. (doi:10.1016/j.cmet.2010.11.011)

Tamada K, Shimozaki K, Chapoval A, Zhai Y, Su J, Chen S, Hsieh S, Nagata S, Ni J \& Chen L 2000 LIGHT, a TNF-like molecule, costimulates T cell proliferation and is required for dendritic cell-mediated allogenic $\mathrm{T}$ cell response. Journal of Immunology 164 4105-4110.

Wu H, Perrad XYD, Wang Q, Perrad JL, Polsani VR, Jones PH, Wayne Smith C \& Ballantyne CM 2010 CD11c expression in adipose tissue and blood and its role in diet-induced obesity. Arteriosclerosis, Thrombosis, and Vascular Biology 30 186-192. (doi:10.1161/ATVBAHA.109.198044)

Xu H, Barnes GT, Yang Q, Tan G, Yang D, Chou CJ, Sole J, Nichols A, Ross JS, Tartaglia LA et al. 2003 Chronic inflammation in fat plays a crucial role in the development of obesity-related insulin resistance. Journal of Clinical Investigation 112 1821-1830. (doi:10.1172/ JCI200319451)

Received in final form 25 September 2013 Accepted 24 October 2013
(C) 2014 Society for Endocrinology Printed in Great Britain
Published by Bioscientifica Ltd. 